\title{
The American Roots of Social Epidemiology and its Transnational Circulation. From the African-American Hypertension Enigma to the WHO's Recommendations
}

Mathieu Arminjon

\begin{abstract}
In 2008, the Commission on Social Determinants of Health at the World Health Organisation published a report demonstrating the existence of a socio-economic gradient for health. Though health inequalities had been apparent since at least the $19^{\text {th }}$ century, the report introduced a bio-psycho-social aetiological model that was absent from 19th century social medicine, as well as from former WHO documents. To bio-psycho-social epidemiologists stress associated with social status is the main cause of morbidity and death.

Here I begin by noting that the history social epidemiologists have written for their field tends to inscribe their work in continuity with $19^{\text {th }}$ century social medicine. This contributes towards minimizing the epistemological and contextual transformations that led bio-psycho-social epidemiology to initiate a profound transformation in international health policy. Adopting an epistemological and transnational perspective, I firstly argue that bio-psycho-social epidemiology emerged from René Dubos' historical and epistemological critique of the foundation of $19^{\text {th }}$ century social medicine. I secondly show how the political and epistemological research program elaborated by Dubos developed in the US context, which was characterized both by a growing concern for chronic diseases and for racial inequalities.

Finally, I show that through its transnational circulation in the United Kingdom, bio-psycho-social epidemiology was "de-racialized". This step was a prerequisite for its aetiological model to be integrated into international public health strategies and to transform them.

Keywords: biopsychosocial, stress, emotions, social epidemiology, René Dubos, Thomas McKeown, WHO
\end{abstract}

Mathieu Arminjon, School of Health Sciences (HESAV), University of Applied Sciences and Arts Western Switzerland (HES-SO), Avenue de Beaumont 21, CH-1011 Lausanne, mathieu.arminjon@hesav.ch 


\section{Making the History of Social Epidemiology}

In 1998, two British social epidemiologists, Richard Wilkinson and Michael Marmot, published a report ${ }^{1}$ on the social determinants of health for the Regional Office for Europe at the World Health Organisation (WHO). In 2005, Marmot was appointed Chair of the Commission on Social Determinants of Health for the WHO. In 2008, the commission published a new report ${ }^{2}$ containing recommendations for closing the gap of social inequalities of health in one generation. Two points arise from these reports: (1) the existence of a socio-economic gradient, that Marmot had summarised elsewhere as "the higher the social position, the better the health", ${ }^{3}$ which is essentially (2) the result of bio-psycho-social stress induced by social inequalities.

Social determinants of health have been central to the WHO's policies since $1948,{ }^{4}$ yet, the reports confirm that a significant epistemological step has been taken: By ratifying the report, the WHO recognised bio-psycho-social epidemiology's most radical thesis: stress associated with social status, is the main cause of morbidity and mortality. In other words, bio-psycho-social epidemiologists managed to completely overturn theories of public health that generally focused on an individual's lifestyle, in favour of the idea that changing social conditions, as well as the way capital is distributed, would make people healthier.

Paradoxically, social epidemiologists minimize the intellectual transformations brought about by bio-psycho-social epidemiology. To Nancy Krieger, Marmot only rediscovered, "with some fanfare", 5 the socio-economic gradient, originally discovered by Louis René Villermé (1782-1863). For some others, social epidemiologists are only "rediscovering the role of the physical and social environment", ${ }^{6}$ or "rediscover the powerful effect of social conditions in shaping morbidity and mortality." If so, one would infer from this "rhetoric of rediscovery" that bio-psycho-social epidemiology is nothing more than a rediscovery of the work and findings of three central figures of $19^{\text {th }}$ century social medicine: Villermé, Rudolf Virchow (1821-1902), and Edwin Chadwick (1800-1890).

Here I argue that these quotations understate aspects of the history of social epidemiology, especially the extent to which the bio-psycho-social

1 Wilkinson/Marmot 1998.

2 CSDH 2008.

3 Marmot 2006, 1304.

4 Irwin/Scali 2007.

5 Krieger 2011, 78.

6 McIntyre/Ellaway 2000, 332.

7 Susser/Myer 2007, 208. 
model emerged as an explicit attempt to operate a rupture with $19^{\text {th }}$ century social medicine. At present, neither the history of public health, nor the history of social epidemiology offer extensive genealogy ${ }^{8}$ able to replace in their context the transformations that paved the way for the development of social epidemiology. This paper intends to help fill that void by retracing the intellectual trajectories that led actors to conceptualize the epistemological foundations of the field.

Given that Marmot and Wilkinson are British, one could expect to find some elements of the history of bio-psycho-social epidemiology's origin in the history of British public health. Through the National Health Service (NHS), British public health culture is historically characterised by what Marmot calls an "obsession with class". ${ }^{9}$ Moreover, in the 1940s-1950s, the "new public health" 10 embodied by a generation of British epidemiologists John Ryle (1889-1950), Thomas McKeown (1912-1988), Jerry Morris (19102009), Geoffrey Rose (1926-1993) - showed a real interest in the social determinants of disease. Dorothy Porter, though, has demonstrated that this interest faded in the early 1960s. ${ }^{11}$

Why insist here on exploring the origin of bio-psycho-social epidemiology from a national perspective? The purpose of this article is to show that the transformation of the WHO's understanding of social inequality is the culmination of a chain of transformations that started in the 1940s-1950s, when a new generation of actors, active in the field of public health, reconsidered, from a historical point of view, the epistemological foundations and effectiveness of $19^{\text {th }}$ century medicine. Analysing McKeown's thesis, I propose adding to the institutional reasons given by Porter, historiographical and epistemological explanations as to why the origin of bio-psycho-social epidemiology should not be sought out in the United Kingdom (UK). The analysis of Dubos' thesis allows me to show that the bio-psycho-social model that Marmot brought to the top of WHO is rooted in the United States (US). It is firstly intimately linked to the emergence of a new etiological model, the elaboration of which was grounded in a very specific interpretation of the epistemological foundation of $19^{\text {th }}$ Century social medicine. Secondly, it found a particular destiny in the US political context, which was marked

8 In an extended Foucaultian acceptance of the term I intend to retrace the intellectual and political statements of the actors, as well as the data they use to construct their discourses. A detailed critical evaluation of the data, especially the way biostatistics was constructed and analysed or judgments about the "veracity" of actor's statements falls out of the limits of this paper.

9 Marmot 2006, 1304.

10 Porter 2011, 165.

11 Porter 2011, p. 182. 
both by the growing concern for chronic diseases and for racial inequalities. That is not to say, though, that the UK context did not play a role in the development of social epidemiology. The adoption of a transnational perspective will allow me to show how its importation and indigenization into the UK has, in the second instance, made possible the kind of de-racialization of bio-psycho-social social epidemiology necessary for the WHO to give bio-psycho-social epidemiology an international aspect.

\section{The McKeown Thesis: Setting the English Stage}

Social epidemiology is today associated with some epidemiologists who, like Marmot, have brought proof of a social determination of health to the top of the international health institutions. Social epidemiology might appear therefore as a specifically Anglo-Saxon endeavour, if not purely English, for its development came after the new figures of British social medicine of the 1950s: John Ryle (1889-1950), Thomas McKeown (1912-1988), Jerry Morris (19102009), Geoffrey Rose (1926-1993). The post-war generation that composed what Porter calls "new public health" 12 developed a strong interest in social determinants of health as a response to their loss of faith in clinical medicine. ${ }^{13}$ Dorothy Porter has demonstrated, however, how a collection of institutional and cultural factors contributed, throughout the 1960s, to the decline of British social medicine. The interest in social determinants of diseases, relying on epidemiological population analysis of the distribution of illnesses according to social stratum, progressively gave way to an analysis of risk factors and the individual responsibility of the patient concerning their health. This is an approach that social epidemiologists like Marmot have fiercely contested. Focusing on the analyses of McKeown reveals exemplary reasons why the origin of bio-psycho-social epidemiology cannot be established in the English "new public health".

In the 1950s, Thomas McKeown, an English physician and Professor of Social Medicine at the University of Birmingham from 1945, published a series of articles ${ }^{14}$ that he brought together in two books, The Modern Rise of Population $^{15}$ and The Role of Medicine: Dream, Mirage, or Nemesis? ${ }^{16}$

12 Porter 2011, p. 165.

13 Porter 2011, p. 115.

14 McKeown/Brown 1955; McKeown/Record 1962.

15 McKeown 1976a.

16 McKeown 1976b. 
These publications consider the explanations normally used for the population increase that marked the turn of the $20^{\text {th }}$ century.

Applying statistics of cause of death collected in England and Ireland since the 1800s, McKeown demonstrates that the population increase cannot be explained by a fall in the virulence of the infectious agent, nor by the progressive resistance of the population to these agents. McKeown aims to show that neither scientific medicine - chemotherapy and vaccination campaigns - nor social medicine and its hygiene measures were responsible for the significant fall in mortality rates either. For tuberculosis specifically, McKeown demonstrates that the mortality rate began to fall in 1838, well before the discovery of bacillus by Koch in 1882 and long before the 1940s, which saw widespread treatment using streptomycin and vaccination by BCG. By process of elimination, then, McKeown defends what has come to be known as the "McKeown thesis": the claim that the demographic and epidemiological transition that began in the $18^{\text {th }}$ century was not attributable to any medical action and should instead be attributed to the rise in living standards as a result of industrialisation. As such, the improvement of food McKeown considered as an epiphenomenon of the economic development - would have made the population more resistant to a wide variety of infectious diseases, in particular tuberculosis.

The McKeown Thesis engendered an array of critiques. ${ }^{17}$ Yet, it nevertheless established a "new orthodoxy"18 that dominated the field of public health in the 1970s-1990s. One could ask whether the McKeown thesis has, for epistemological reasons, played a major role in what Porter identified as the decline in interest for social determinants of diseases in the United Kingdom. As noted by Szreter ${ }^{19}$ by promoting a liberal assumption that health inequalities would "naturally" disappear along with improved living standards accompanying the post-war economic boom - an assumption that would later prove to be flawed ${ }^{20}$ - the McKeown Thesis led to a paradox: he simultaneously celebrated social medicine, and, at the same time, nullified any reason for studying how social disparities might affect health, as well as the public health strategies that might seek to reduce them. This "laissez-faire" attitude towards public health, though, contrasted sharply with the thesis supported across the Atlantic by Dubos.

17 Condrau/Worboys 2007; Mackenbach 1996; Szreter 1988.

18 Colgrove 2002.

19 Szreter 2002.

20 For instance, Richard Wilkinson and Pickett (2009) showed that health inequalities are not associated with absolute, but relative poverty. In other words, improving living standard cannot reduce health inequalities on its own, whereas reducing the socioeconomic gap between the disadvantaged and the privileged can. 


\section{The Dubos Thesis: Setting the American Stage}

These kinds of historico-epidemiological inquiries into the role played by medicine in the eradication of infectious diseases, principally associated today with McKeown's name, were not entirely new. The subject had already been addressed several years earlier by René Dubos. Born in France, this agronomist by training pursued his career as a biologist in the United States. He published several books, ${ }^{21}$ which had some impact in the US, especially on the radical criticism of medicine. ${ }^{22}$

Before McKeown, Dubos claimed that laboratory medicine was not responsible for the drop in mortality rate caused by tuberculosis that began to plummet before the discovery of the infectious agents and ad hoc treatments. Dubos, however, came to a radically different historiographic conclusion. To him the "invisible hand" 23 of economic development and the rise in living standards do not explain the demographic explosion. According to Dubos, it was due to the political and medical initiatives that upholders of social medicine undertook in the $19^{\text {th }}$ century. Villermé, Virchow and Chadwick, amongst others, undoubtedly played a key role in putting in place better hygiene measures, increasing the cleanliness of towns and improving the quality of water and food, etc. Yet, if these actions were indeed effective, states Dubos, it was for ideological reasons and not based on solid scientific foundations: "the conquest of epidemic diseases was in large part the result of the campaign for pure food, pure water, and pure air based not on a scientific doctrine but on philosophical faith". ${ }^{24}$

Social medicine, which stood in opposition to germ theory, supported a hygienist morality with Hippocratic tendencies. ${ }^{25}$ For Dubos, there can be no biomedical justification for the recommendations of social medicine, calling for the restoration of harmony between man and the "natural" environment, a relationship hindered by industrialisation and growth in urbanisation. If Dubos grants social medicine the effectiveness that McKeown refuses to acknowledge it, he does not discredit its scientific and political value any less. It is precisely on this point that Dubos's analysis advances not only as a personal criticism of the triumphant historiography of $19^{\text {th }}$ century medicine, but also, and above all, as a systematic consideration of what the foundations of a future medicine should be.

21 Dubos 195919611965.

22 Sedgwick 1973.

23 Szreter 2002, 722.

24 Dubos 1959, 151.

25 Dubos 1959, 145. 
Criticising further the triumphs generally attributed to scientific medicine, Dubos writes:

It can be stated with great assurance that most of the persons present in the very room where [Koch] read his epoch-making paper in 1882 had been at some time infected with the tubercle bacilli (...). At the time, in Europe, practically all city dwellers were infected, even though only a relatively small percentage of them developed tuberculosis or suffered in any way from their infection. ${ }^{26}$

If the entire population was infected with Koch's bacillus, why did the tuberculosis mortality rate fall first in the better-off classes? Is it that the infectious agent should no longer be considered the cause of disease, but rather the susceptibility of the individual determines their resistance or vulnerability to the pathogen? Dubos expresses this displacement of the medical interrogation process by re-appropriating the words of Bernard Shaw: "The characteristic microbe of a disease might be a symptom instead of a cause". ${ }^{27}$ Yet, if it is to be believed that the figures demonstrate a drop in mortality rate caused by tuberculosis in the better-off classes first of all, then the "susceptibility of the host" 28 directly depends upon their socio-economic status. In other words, analysis of the social and epidemiological data has highlighted a shift concerning the problem of the aetiology of disease, displacing the focus from the infectious agent to the susceptibility of the host, and the susceptibility of the host to the socio-economic status of the diseased person.

Dubos' criticism drew radically different conclusions from McKeown's. By only attributing the fall in mortality level to the "invisible hand" of economic development, the epidemiological transition is seen to be completely disassociated from medical action and knowledge, whether or not these were social or scientific. According to Dubos, in fact, "the provocative cause of microbial disease may be a disturbance in any of the factors of his external or internal environment - be that weather conditions, availability of food, working habits, economic status, or emotional stress". ${ }^{29}$ In 1965, Dubos was more specific about the identification of environmental factors:

The microbial disease most common in our communities today arises from the activities of microorganisms that are ubiquitous in the environment, persist in the body without causing obvious harm under ordinary circumstances, and exert pathological effects only when the infected person is under conditions of physiological stress. ${ }^{30}$

26 Dubos 1959, 105.

27 Dubos 1959, 83.

28 Dubos $1959,83$.

29 Dubos $1959,93$.

30 Dubos 1965, 164. 
The relationship between social conditions and "stress" prefigures what would come to be the central concept of social epidemiology, that of "bio-psychosocial stress".

It is thus on the basis of his criticism of medicine, and the epistemological displacement concerning the aetiology of disease, that Dubos formulated what he imagined would be the political and scientific programme for medicine in the second half of the $20^{\text {th }}$ century:

It is not impossible that in the future, as in the past, effective steps in the prevention of disease will be motivated by an emotional revolt against some of the inadequacies of the modern world (...) This attitude need not mean a retreat from science - far from it. The crusade for pure air, pure water, pure food was at the best a naïve and often ineffective approach to the problem of health of the Nineteenth Century, but it paved the way for the scientific analysis of the factor responsible for the epidemic climate of the Industrial Revolution. Similarly, scientific medicine will certainly define the factors in the physical environment and the types of behaviour, which constitute threats to health in modern society. ${ }^{31}$

To sum up Dubos' analysis, it can be understood that the type of link that social medicine and its hygienist ideology was able to establish, between the economic status of individuals and their vulnerability to a certain disease, revealed a bio-statistical correlation at best. To Dubos, if a modern social medicine is to emerge, it must be supported by a testable causal physiological model. Therefore, it is the opposition between social medicine on the one hand, and laboratory medicine on the other, which must be reconsidered with the aim of clarification. Laboratory medicine, which until then had focused all its attention on the isolated external cause - the mono-causal infectious agent - should look towards incorporating the susceptibility of the host into its research including psychosocial variables in its protocol. Doing so, it would be able to replace social medicine's ideological justification with experimentally justified explanations. This is the analysis and related research program elaborated by Dubos that the first generation of bio-psycho-social epidemiologists, such as John Cassel, would go on to carry out based on what Dubos identifies as an "emotional revolt" against racial health inequalities.

31 Dubos 1959, 219. 


\section{Social Epidemiology: Racial inequalities before the Bio-Psycho-Social Model}

According to the American Constitution, ratified in 1787, the "people of the United States" are the sovereign political authority of the nation. Accordingly, Article I, Section 2 states that:

Representatives and direct taxes shall be apportioned among the several states which may be included within this union, according to their respective numbers, which shall be determined by adding to the whole number of free persons, including those bound to service for a term of years, and excluding Indians not taxed, three fifths of all other Persons. The actual Enumeration shall be made within three years after the first meeting of the Congress of the United States, and within every subsequent term of ten years, in such manner as they shall by law direct.

The representation of the sovereign people thus requires a federal census to determine, in proportion to the population of each state, the amount of federal taxes they will have to pay, as well as the number of seats they will have in the House of Representatives. To this end, the U.S. Census Bureau was formed every decade until 1902, when it was perpetuated.

In this context, the status of individuals resulting from the slave trade becomes a central political issue. The representatives of the southern states, in favour of slavery, had the largest population of slaves. They therefore had a strong interest in defending their census in order to obtain more seats in the House of Representatives. The northern states, in favour of the liberation of slaves, rejected the proposal on the pretext that slaves could not be both property and representative citizens. A compromise was reached: each state would count the free individuals, to which would be added three-fifths of the "other persons". On this basis, the first census, conducted in 1790, counted white men and women and slaves.

The office's mission was originally limited to the census of inhabitants, it meant by no means to collect vital statistics. It was around the $1840 \mathrm{~s}$, based on the methods implemented in England and Wales under Chadwick's leadership, that the first registers of births, deaths and causes of death were created. It was not until the end of the civil war that the American Public Health Association was founded in 1872 and then, in 1879, the National Board of Health, which aimed to generalize the collection of vital statistics at the national level.

In 1880, John Shaw Billings, a former medical statistician in the Potomac army, became president of the National Board of Health's Committee on National Statistics and was responsible for organizing the decennial census. In 1890, the first "modern" census was issued, incorporating vital statistics. When in 1946 the responsibility for collecting biostatistics was transferred 
from the Census Office to the National Office of Vital Statistics of the U.S. Public Health Service, racial categories could have disappeared. They were, however, renewed as they stood. In the meantime, the availability of epidemiological data, has allowed US public health institutions to show the existence of a racial gap.

To Krieger, the term "social epidemiology" first appeared in a paper by Alfred Yankauer, ${ }^{32}$ a Harvard graduate and of Professor of Family and Community Health at the University of Massachusetts from 1973 to 1990. At the end of three years training spent as a Health Officer for the New York City Department of Health, Yankauer published a study based on the 1940 census figures. The paper, entitled "The Relationship of Foetal and Infant Mortality to Residential Segregation: An Inquiry into Social Epidemiology", ${ }^{33}$ demonstrates that: "in New York City neighbourhoods both white and Negro foetal and infant mortality rates increase as the proportion of $\mathrm{Ne}-$ groes in the neighbourhood increases". ${ }^{34}$ Yankauer explains that in the overpopulated ghettos rent prices are proportionately higher, hygiene conditions poorer and access to high quality and varied foods is more limited. Members of the black community are faced with materially degraded living conditions and oversubscribed medical institutions. Weaker financial resources for food and healthcare further exacerbate this. Yankauer's study closes with a plea for taking large-scale action for desegregation by breaking down the barriers causing residential division.

Yankauer's integration of social epidemiology into social medicine, is not only apparent in the reference to Virchow that concludes his paper: "Medicine is a social science and politics nothing but medicine on a grand scale." It is also apparent on the epistemological front. To him, social epidemiology remained an analysis of the socioeconomic material conditions of health. It limited itself to the correlation between the state of health and accessibility to certain necessities, such as quality of food or access to adequate healthcare. Moreover, the term "social epidemiology" appeared as limited to revealing sociological correlations. It did not, therefore, offer analysis of the pathophysiological mechanisms, i.e. the physiological vulnerability or susceptibility to diseases, likely to explain the causal link between social status and the state of health of an individual. By incorporating a racial factor, Yankauer did introduce a new social determinant. He did not, however, handle racism in terms of being a social construct concerning racial/social relations. He reduced it, rather, to simply considering geographical segregation.

32 Yankauer 1950.

33 Yankauer 1950.

34 Yankauer 1950, 646. 
This is the very reason why Yankauer claims that as the "proportion of Negroes" rises, foetal mortality rises both for white and black people. Racial relations are thus reduced to being structural socioeconomic components concerning material living conditions or level of access to certain goods or services. If one can suppose that those determinants truly induce a "physiological stress", their influence is indistinguishable from racial/social status. In other words, Black people living in a white neighbourhood would have the same foetal mortality as their white peers. Finally, this social epidemiology essentially remains an epidemiology of social resources and physiological "lacks" of primary physiological needs, and healthy environments. It always presupposes - something McKeown would not have disapproved of that a general improvement in living standards (better access to decent food, to medical care etc.) leads systematically to an improvement in health.

If so, the economic boom in the US should have been accompanied by an improvement in the living standards of African-Americans. If the increase in living standards did improve health in the African-American community ${ }^{35}$, the racial gap between blacks and whites remained and was transferred to include chronic diseases that are associated with the development of industrialized societies. As we will shall see, modern social epidemiology emerged exactly when the explanations mobilized in order to account for racial health inequalities in the US, especially chronic disease, switched focus from the external pathogenic conditions or agents (the presence of a noxious agent or the lack of access to primary needs), to the social conditions determining what Dubos called the susceptibility of the host.

\section{Chronic Disease within an Ethnocentric Pathophysiology}

George Weisz ${ }^{36}$ documented how US public health institutions, more quickly than other nations, gradually transferred their focus from communicable diseases - that were not considered as the major cause of death anymore - to chronic diseases. The reorganisation of the health services at the beginning of the $20^{\text {th }}$ century ${ }^{37}$ then by the "Welfare" politics following the "New Deal" initiated by Roosevelt at the brink of the 1929 crisis, fed a deep concern for what was identified as an "unseen plague". ${ }^{38}$ Armstrong ${ }^{39}$ has shown how in

35 Williams 2001.

36 Weisz 2014.

37 Weisz 2014, 30.

38 Boas, 1940.

39 Armstrong, 2014. 
the first half of the $20^{\text {th }}$ century, it has widely been agreed that a rise in life expectancy causally explained the rise in the prevalence of degenerative diseases such as hypertension. In 1934, Charles Stone confirmed, "Arteriosclerosis, as we know it, is bound by the laws that govern the average age of a species. It is ultimately inevitable, therefore, and not subject to change". ${ }^{40}$ Arterial hypertension was then generally seen to be "essential", i.e. the result of the natural degeneration of vascular tissue occurring in an aging population. This idea was apparently corroborated by epidemiological statistics demonstrating that hypertension affects the entire population and its prevalence gradually increases with age. If the disease is essential, then the medical profession can only delay the effects of an inevitable process. It was necessary to wait until the 1950s, when the first results of the Framingham Heart Study were issued and the notion of (individual) risk factor emerged for behavioural aspects (alcohol consumption, lifestyle etc.) and predisposing conditions (hypertension, obesity, cholesterol etc.) to challenge the theory of the "essentiality" of hypertension. Yet, another and less documented field of research, focusing on solving what appeared to be an enigma, the high prevalence of hypertension in the African-American community, also contributed to these transformations.

In the 1930s, census figures had already revealed that black people suffer more pathologies and have a higher death rate than white people. The evaluation of the impact of chronic disease on economic life also revealed a racial disparity. Black workers had a higher level of invalidity than white workers $^{41}$ and it is also notable that in a workforce employed by the same company, black workers tended to have a higher blood pressure than white workers..$^{42}$ More importantly, the figures from the 1930s to the 1960s census demonstrate a strong and ever-increasing prevalence of a specific disease in the African-American community - arterial hypertension - the causes of which remained hypothetical.

In 1957, Lennard and Glock ${ }^{43}$ listed four hypotheses along with their respective limitations. (1) The hypothesis of "physical exertion" incorporates the theory of the "economic gap": African-Americans work in the lowest paid professions and those that, as a result, require the greatest physical effort. There is no data, however, to suggest a link between physical effort and a rise in blood pressure. On the contrary, physical activity has been seen to reduce the risk of coronary disease. (2) Abram Kardiner and Lionel Ove-

40 Stone, 1934.

41 Britten 1934.

42 Adams 1932.

43 Lennard/Glock 1947. 
sey ${ }^{44}$ suggested an alternative explanation: hypertension could be linked to "psychological conflicts" that are the result of suppressed feelings of aggression and emotional stress induced by the psychological pressure placed by whites on African-Americans. Lennard and Glock note, however, that this psychoanalytically inspired theory could not be validated as it was only based on interviews that took place with 25 individuals. (3) The "associated disorders" hypothesis views hypertension as a disease associated with syphilis or pyelonephritis. For the authors, the studies on the subject seem, though, to lead to contradictory results. (4) Finally, the theory of a genetic trait that predisposes Black people to hypertension always finds its defenders. The authors note, however, that the figures here are lacking. To validate this theory, it would be necessary to demonstrate that "a racial disposition to hypertension would be manifested in a higher occurrence of hypertension among Negroes than among whites wherever they may be located". ${ }^{45}$

The problem of the prevalence of arterial hypertension in general, and in the African-American community in particular, might thus require comparative physiological study. By questioning the universality of the general pattern of arterial tension recorded in the western world, epidemiologists operated a major epistemological reconfiguration. By introducing the concept of "cross-cultural" epidemiology of hypertension ${ }^{46}$ they acknowledged that biomedicine raised the physiological parameters of the white man to the rank of being normal, natural and thus, universal. As we shall see, in assuming that physiology might have had ethnocentric presuppositions - a methodological bias believed to be limited to the social sciences - cross cultural epidemiology finally opened the way for a study of the physiological parameters, incorporating hitherto unseen variables, be they racial, cultural or socio-economic.

\section{Towards a Socio-Cultural Epidemiology of Hypertension}

Validation of the essentialist thesis required that the cultural variability of arterial hypertension be tested. The cross-cultural epidemiology of hypertension was an important step towards displacing the focus from cultural to social determinants of hypertension. I will here re-examine this change of focus to show how it progressively oriented epidemiologists towards identifying

44 Kardiner/Ovesey 1951.

45 Lennard/Glock 1957, 191.

46 Lennard/Glock 1957, 192. 
social stress, rather than any ineluctable biological determinism, as a main aetiological factor for hypertension.

In a review paper Jack Geiger and Norman A. Scotch ${ }^{47}$ count over one hundred studies aimed at measuring the "socio-cultural" variability of arterial tension. The oldest dates back to $1916 .{ }^{48}$ Out of these hundred or so studies, only nineteen demonstrate homogenous samples allowing for the comparison of twenty-two different societies on the basis of age and sex. The authors reveal a certain variability concerning the average blood category for people aged from 46 to 65 years old. The lowest result for both sexes $(105 / 68)$ is found amongst the Kuna Indians from the north of Colombia. The highest measurement of blood pressure was recorded amongst the inhabitants of the United States Virgin Islands ${ }^{49}$ The results recorded in this group of Caribbean Islands under American administration since 1917, enabled comparison of the vital statistics of black and white inhabitants of the archipelago, and could then be compared with Americans living on the mainland. In the US, the average blood pressure is between 142/85 for men and $144 / 85$ for women. In the white community of the Virgin Islands it is $146 / 86$ for men and 148/86 for women. In the black community, this rises to $156 / 93$ for men and 169/98 for women. For Geiger and Scotch, the fact that whites on the Virgin islands have a higher blood pressure than Americans on the mainland leads them to believe that the difference is mainly the result of socio-economic factors affecting all "races" and, in particular, the Blacks, who are the least materially privileged: "the inhabitants of the Virgin Islands are generally poor; they suffer from vitamin deficiencies; and both negroes and whites have higher blood pressure than persons in the United States". ${ }^{50}$ For others, though, such as Alfred Moser, this study, as well as others that are similar carried out in the Belgian Congo, Ruanda Urundi, North Rhodesia, Liberia and South Africa, seems to corroborate the theory that "elevated blood pressure does occur even in some primitive tribes". .51

It is pertinent here to establish the author's understanding of "primitive tribe". Moser is fully aware of the fact that the studies carried out up to then were subject to methodological misgivings hindering a true physiological

47 Geiger/Scotch 1963.

48 Concepcion/Bulatao 1916.

49 Saunders/Bancroft 1942.

50 Saunders/Bancroft 1942, p. 422.

51 Moser 1960, 989. 
comparison likely to determine if hypertension found amongst African-Americans is genetically caused or not:

Unfortunately, until now direct comparisons of data on the prevalence of hypertension among Negroes from Africa and the United States have not been possible since adequate blood pressure surveys have not been carried out on the west coast of Africa (Ghana, Liberia, and French Equatorial Africa), the points of origin for Negroes brought to the New World. Most of the data reported to date has been from South Africa and east Africa, areas where the population may differ considerably from the American Negro. ${ }^{52}$

Moser notably refers to a study carried out in South Africa ${ }^{53}$ involving post mortem analysis of the cardiovascular systems of 194 white South Africans of European origin and 346 of the Bantu peoples, a linguistic community, that although migrating east as well as south in Africa originally came from west Africa. The authors, however, show that in their cohort, "the majority of the adult Bantu subjects spent their childhood in rural areas and moved to urban areas after the age of about 16 years". ${ }^{54}$ In a similar way, Moser's study was also meant to involve "primitive people", and in fact involved "the entire populations of two small villages separated by approximately 50 miles in $\mathrm{Li}$ beria, Africa, and of young, healthy male tappers at the Firestone Plantation in Liberia". ${ }^{55}$ In both cases, just like in the Virgin Islands study, the populations termed "primitive" come in fact from towns, rural village settlings or even plantations. The choice of populations is therefore full of assumptions according to which there is a predisposition towards hypertension independent from social environments (rural, town, plantations ...).

Scotch ${ }^{56}$ carried out his own study of "socio-cultural" factors of hypertension in order to avoid these pitfalls. During a two-year long research trip in South Africa he studied the blood pressure levels of a group of Zulus living in a reserve that, in spite of living in a certain amount of poverty, maintained a traditional way of life relatively unaffected by Apartheid. Their blood pressure was compared with that of the Zulus that migrated, for economic reasons, to Durban where "police harassment and arrest, a daily fact of life, must be seen as stressful in the extreme". ${ }^{57}$ The blood pressure of the two groups of Zulus was eventually compared with that of the white community and that of the African-Americans of Comstock, Georgia, in the south of the United States. These measurements allowed Scotch to reveal a socio-cultural gradient: "the rural Zulu have the lowest mean blood pressure,

52 Moser 1960, 989.

53 Meyer et al. 1964.

54 Meyer et al. 1964, 415.

55 Moser, p. 993.

56 Scotch 1963.

57 Scotch 1963, 1205. 
the white Georgians are somewhat higher, the urban Zulu are still higher, and the Georgia Negroes are highest of all" ${ }^{58}$ Since the rural Zulus show a lower blood pressure than the white population in the United States, the theory of an intrinsic deficiency of the "black race" seems to lose all validity. It is further weakened by the fact that the study demonstrates a correlation between duration of residence in the city and rise in blood-pressure: "the longer the residence, the more the hypertension". 59

Yet, if we return to the summary article of Geiger and Scotch, which details nineteen studies comparing twenty-two different societies, it is noteworthy that, although black men and women from the Virgin Islands have the highest blood pressure, the lowest was recorded in the Kuna Indian community. Not only is it low, but it is also equal for both sexes and shows no variation according to age. Recognisable here, is the characteristic pattern of blood pressure such as it has been measured in truly "primitive" populations, i.e. populations where the social organisation has not been affected by sedentariness, agriculture and industrialisation. In 1967, collaborations between cardiologists, epidemiologists and anthropologists allowed for the study of completely undisturbed hunter-gatherer communities in West Africa. ${ }^{60}$ The results, ratified many times since, ${ }^{61}$ attested to the fact that the pattern of blood pressure in the Kuna Indians, low for both sexes and not increasing with age, is unique to the hunter-gatherer communities. These results helped to establish a theory of social variability of hypertension, given that it is primarily the type of socio-economic organisation, more than culture, which proves to be decisive. The causal connection between stress and social structure, however, still required clarification.

\section{John Cassel: A Bio-Psycho-Social Epidemiology}

During the 1960s, the hypothesis that bio-psycho-social stress causes arterial hypertension in the African-American population was still based on epidemiological correlations. As we shall see, the combination of Dubos' programme of research, on the one hand, and the epidemiology of hypertension

58 Scotch 1963, 1207.

59 Scotch 1963, 1208.

60 Epstein/Eckoff 1967.

61 This was only briefly contested by the hotly debated bio-historical hypothesis of Wilson/ Grim 1991, which stated that slaves possessing a sensitivity to salt, therefore retaining more sodium and water, would have had a selective advantage allowing them to withstand the transport conditions to America as well as the conditions of life on a plantation. For a critique see Curtin 1997. 
on the other, allowed John Cassel to provide a causal relation and redefine the object of social epidemiology as the study of the bio-psycho-social determinants of disease. Once again, arterial hypertension in the African-American community played a paradigmatic role.

In 1970, Sole Levine and Scotch published a collection of works under the title Social Stress. For the authors, this publication developed because, until then, no "systematic discussion of the conceptual and methodological issues of the sources and the consequences of social stress" 62 existed. The prevalence of arterial hypertension in the African-American community appears as a paradigmatic example:

We can agree that Negroes suffer from more stress experiences and also have a higher prevalence of hypertension. Unfortunately, it is at this point that epidemiologists - at least until recently - have failed to pursue the question and to test the relationship of stress experiences to the development of hypertension. ${ }^{63}$

Why have things recently changed? In fact, the work of John Cassel, who contributed to the publication, ${ }^{64}$ made significant headway in the field. For Cassel, the mass of epidemiological cross-cultural data cannot alone provide the answer to the question of the non-universality of hypertension, but it at least constitutes a guiding light of evidence:

Despite the weakness of each study taken individually a rather extraordinary concordance of results is obtained when reviewing all the studies simultaneously. Thus studies on the level of blood pressure conducted over the last 30 years in many countries across the world (...) have universally shown populations living in small cohesive societies "insulated" from the changes that are occurring in the Western industrializing countries, with low blood pressure that do not differ in the young and the aged. ${ }^{65}$

By explicitly transposing Dubos' conceptions of socially determined "susceptibility of the host", from infectious to chronic disease, Cassel deduces:

From the data summarized thus far, it would appear not unreasonable to expect that the more precise identification of some of the social processes hinted at could yield important new information on some of the sources of physiological stress that Dubos maintains "convert latent infection into overt symptoms and pathology. ${ }^{66}$

The short yet prolific career of Cassel contributed towards bringing the aetiological displacement highlighted by Dubos into the field of social epidemiology in general, in order to apply it more specifically to its prototypical object. Biographical reasons may explain Cassel's interest in the prevalence of high blood pressure in the African-American community. Cassel came from

62 Levine/Scotch 2013[1970], 10.

63 Levine/Scotch 2013[1970], 5.

64 Cassel 2013[1970].

65 Cassel 2013[1970], 196.

66 Cassel 2013[1970], 200. 
South Africa where he developed clinics for Zulu groups that lived in the margins of South African society. When Apartheid was in full force in 1948, all racial mixing, including medical practice, became illegal and was punishable by death. Cassel and his wife, a nurse, were exiled from the country in 1953. They landed in England before settling definitively in the US, where he became the Director of the Department of Epidemiology School of Public Health at the University of North Carolina in 1958. Despite the lack of information available concerning Cassel's life, his political commitments can be indirectly presumed. Cassel belongs to a generation of South African doctors, nurses, and epidemiologists, forced into exile and established in the US because of their will to develop socio-medical institutions devoted to racial minorities. Emily and Sidney Kark were also forced into exile in 1958 and Zena Stein and Mervin Susser were expelled in 1955. One can imagine that Cassel shared the views of the latter who was overtly militant against the Apartheid and for social justice, not hesitating to put the situation of African minorities in South Africa and African-Americans into perspective in the US. ${ }^{67}$ Consequently, Cassel had many reasons to be "emotionally revolted" by racial health inequities (to use Dubos' words) and sensitive to the civil rights movement dominating the US throughout the 1960s-1970s. Endeavouring to provide experimental and neurophysiological justification for the epidemiological correlations, he set about literally carrying out the political and scientific programme envisaged by Dubos.

A year prior to his contribution to Levine and Scotch's book in the American Journal of Epidemiology, Cassel published an article with the physiologist James Henry ${ }^{68}$ In it, they detail the general spectrum of data considered to be potential causes of high blood pressure. Cross-cultural epidemiology, however, seemed to indicate that the risk factors generally suggested by epidemiologists - diet, tobacco, salt consumption, obesity or even inheritance - were only aggravating factors rather than the direct and external causes of hypertension. The two authors refer to a study led by Henry, which involved isolating young mice from their birth before reintroducing them into the "social" group at maturity. Henry compared the physiological effects of diet (intake of caffeine, salt etc.) to those of the disorganisation of the "social hierarchy". If diet seemed to have little effect, chronic "social stress", experimentally induced, strongly correlated with the appearance of peptic ulcers and high blood pressure.

67 See for instance Susser 1983.

68 Henry/Cassel 1969. 
For Cassel, Selye's General Adaptation Syndrome ${ }^{69}$ combined with Dubos's conception of the susceptibility of the host, was the kind of integrative explanation that could causally explain how bio-psycho-social stress causes disease in general and hypertension in particular. To Selye, chronic stress engendered by the effort necessary to adapt, leads, via activation of the hypothalamus and the pituitary gland, to a reaction of alarm, followed by resistance, then a state of general exhaustion at which point multiple diseases appear. ${ }^{70}$ Cassel does not hesitate to make the connection between the "social deprivation" experienced by mice and the mortality rate linked to cardio-vascular disease:

The alarm response induces modifications of the steady state condition, which activate adaptive mechanisms. There is evidence that by acting repeatedly over the years, this defence reaction will lead to a chronic elevation of systolic arterial pressure in the majority of the members of a disturbed social group. ${ }^{71}$

Cassel found, in Henry's experiments with mice, the operationalization of Dubos experimental project, which aimed to bring "social" variables into the laboratory. Yet, Cassel also extended Dubos' experimental appeal outside the laboratory. It was through his efforts to objectivise the causal links between stress and social relationships that the case concerning the prevalence of high blood pressure in the African-American community reappeared as a paradigmatic case study. Cassel led a research project with Neser ${ }^{72}$ studying the mortality rate as a result of cardio-vascular attack in one hundred counties of North Carolina classed according to the Smith Index. The index gives a score of "social disorganisation" considering family instability, illegitimate birth rate, rate of imprisonment and divorce rate. The study revealed, in the African-American community, and not in the white community, a correlation between mortality rate and the level of social disorganisation. Additionally, this gradient proved to be independent of absolute poverty of individuals and of physical environmental conditions. Coming back to these findings in 1976, Cassel concluded:

In animal experiments, changes in the social milieu have their most marked and dramatic effects on the health and endocrine status of subordinate animals, with dominant ones showing the least effects. Perhaps these findings reflect the subservient role the Blacks (until perhaps recently) have been forced to occupy in our society. The second speculation is the possibility that in the face of social disorganization Whites have more resources, including sources of social support to help buffer their physiologic processes from these effects. ${ }^{73}$

69 Selye 1952.

70 For a detailed study on the history of stress and its links with social epidemiology see Arminjon 2016.

71 Henry/Cassel 1969, 1895.

72 Neser/Tyroler/Cassel 1971.

73 Cassel 1976, 116. 
Due to his premature death in 1976, Cassel could not continue his research. His work did, nevertheless, go on to profoundly affect future developments in social epidemiology.

For instance, Nancy Krieger, a figurehead in American social epidemiology, acknowledges, in a theoretical paper, that social epidemiology benefitted substantially from Cassel's findings (Dubos only earns a footnote) ${ }^{74}$ But she also points out that the bio-psycho-social framework pays too much attention to physiological resources and not enough to the social, political and economic policies that generate psychosocial inferiorities. Paradoxically, despite her critics, her empirical work is firmly rooted in the US social epidemiological tradition from which she employs the epistemic object and bio-psycho-social model. In 1996, Nancy Krieger, and Stephen Sidney, published their research, the significance of which is summarised in the following way: "our results indicate that racial discrimination shapes patterns of blood pressure among the US Black population and Black-White differences in blood pressure". ${ }^{75}$ They were able to measure that African-Americans claiming never to have experienced racial discrimination had higher blood pressure than those who recognised that they had been the object of discrimination and were in the habit of fighting against it. They thus brought back into fashion the theory supported thirty years earlier by Abram Kardiner and Lionel Ovesey $^{76}$. Racism, redefined as stress induced by social stigma, is one of the psychosocial causes of high blood pressure, especially when internalised. Like Cassel, they demonstrated that the fact of being black in the USA implies assuming a social "role" which determines state of health even more than absolute poverty. This social role not only determines the type of relationships that individuals share with their community and the rest of society, but, moreover, their inner life, both psychologically and biologically. Indeed, individuals inclined to share and condemn their experiences of discrimination create around themselves the community and social support required to buffer the detrimental physiological effect of social stigmatization.

\section{Bio-psycho-social Epidemiology: From the Local to the Global}

If the work of Krieger, amongst others, ${ }^{77}$ testifies to the fact that social epidemiology is not historically dissociable from the racial issues specific to the

74 Krieger 2001, 670.

75 Krieger/Sidney 1996.

76 Kardiner/Ovesey 1951.

77 Williams 2001. 
US's public health system, we are bound to go on to consider the process of transnational circulation that de-racialized the discipline and made it an international health issue.

After an undergraduate degree in medicine Marmot undertook a Ph.D. at the Berkeley School of Public Health, under the direction of Syme, a sociologist given the title of professor of epidemiology in 1968. Syme ${ }^{78}$ suggested he study the case of Japanese people living in California who found themselves five times more likely to contract coronary heart disease than people living in Japan. Marmot demonstrated that the Japanese living in California, who had maintained a traditional style of life, had no more of a coronary risk than the Japanese living in Japan. ${ }^{79}$ Syme's influence on Marmot was two-fold.

Firstly, Syme remains attached to the bio-psycho-social model. He admits the debt his work owes to Cassel. ${ }^{80}$ For instance, in an article seeking to open the way for future research in social epidemiology, Syme and Berkman state: "The proposal offered here is that those in the lower classes consistently have higher rates of disease in part due to compromised disease defences and increased general susceptibility" ${ }^{81}$ The notion of "general susceptibility" here invokes Dubos by way of Cassel. Secondly, this passage also demonstrates that if Syme aligns himself with American public health issues, he also distances himself from them. By introducing the notion of "social class", he recognises that American social epidemiology is intimately linked to the health inequalities suffered by racial minorities and that these local public health issues should not hide the fact that general susceptibility to diseases concerns all the social classes. Syme, in fact, recalls that if Black people have a higher rate of hypertension than white people, a "social class gradient" ${ }^{2}$ can also be measured within the African-American community, as well as within the white community. For Syme, these facts "suggest that something about lower social class position may be involved over and above any racial influences". ${ }^{83}$ It is both the bio-psycho-social model and the concept of the social gradient, expanded to incorporate all social classes and not simply the African-American community, that Marmot went on to import and implement in the United Kingdom.

With his Ph.D. completed in 1976 Marmot joined the London School of Hygiene and Tropical Medicine. There he encountered Geoffrey Rose, one

78 Syme 2005.

79 Marmot/Syme 1976.

80 Syme 2005.

81 Syme/Berkman 1976, 6.

82 Syme et al. 1974, 619.

83 Syme et al. 1974, 620 . 
of the instigators of the Whitehall Studies. Initiated in 1967 and completed in 1969 , the Whitehall study sought to analyse the prevalence of cardiovascular diseases and mortality rate in a cohort of more than 1800 British male civil servants aged between 40 and 64 . Although the study examined the state of health of a population of civil servants chosen for the fact that they would be representative of the British social hierarchy, it had not actually been conceived for the purpose of studying health differences according to class. In the papers published before the arrival of Marmot, Rose and his collaborators ${ }^{84}$ were only interested in individual lifestyle factors such as early myocardial ischaemia, which is a predictor of mortality by coronary heart disease (CHD). Marmot established the existence of a socio-economic gradient, the implications of which ran counter to the previous analyses focusing on individual risk factors: "the higher CHD mortality experienced by working class men, which is present also in national statistics, can be only partly explained by the established coronary risk factors" ${ }^{85}$

The reference to "national statistics" gives some idea of the British public health culture into which Marmot would integrate the contributions of bio-psycho-social epidemiology. If social medicine was in decline during the 1960s, there at least existed a tradition of analysing the state of public health in terms of social status. This was made possible by the previous epidemiological system that had been established at the turn of the $20^{\text {th }}$ century. Before the creation of Britain's health institution, the National Health Service (NHS), in 1948, monitoring the UK population's state of health was carried out by the collection of vital statistics - birth, death and cause of death - every ten years following the first census in 1913. In contrast with the United States, the British census has only recently started collecting information linked to race. On the other hand, data concerning the socio-economic status of individuals was collected from the outset and divided into the 5 categories of the General Registrar's social classes. ${ }^{86}$ As Marmot recalls, the availability of vital and social statistics, which would also be used in the Black Report ${ }^{87}$-another large study of social determinants in the United Kingdom based on census data - revealed, from 1978 onwards, a link between social class and cardiac disease. It is this culture of public health that Marmot would eventually revive. But by mobilising the bio-psycho-social model, brought over from the United States, Marmot primarily introduced

84 Rose et al. 1977.

85 Marmot/Rose/Shipley/Hamilton 1978, 244.

86 (I) Professional and Managerial, (II) Intermediate, (III.1) Non-manual, (III.2) Manual,

(IV) Semi-skilled Manual, (V) Unskilled Manual.

87 Department of Health and Social Security 1980. 
into the Whitehall Study, and thus into the British culture of health, a hitherto unseen aetiological perspective:

A variant of this general explanation, proposed by Berkman and Syme and by Cassell is that psychosocial factors (stress) influence susceptibility to various specific insults. We have documented marked psychosocial differences between civil service grades and these will be reported elsewhere. ${ }^{88}$

When Marmot launched the Whitehall Study II, though, from 1985 to 1988, it was specifically in order to refine the study of the causes of the social gradient, placing all attention on the "psychosocial factors which may influence health, with a focus on stressful work environments and lack of social support as they may influence risk of cardiovascular disease". ${ }^{89}$ This second section of the study confirmed the existence of a socio-economic gradient. It also showed that individuals of a socially inferior level, for whom the cardiovascular risks are increased, had a larger workload with less varied work, which left no room for learning. More than hereditary factors, lifestyle risk-factors, level of absolute wealth or an individuals' behaviour, it is an individual's social role that determines their state of health:

Social participation should not be seen as simply a characteristic that high-status individuals are fortunate enough to have in abundance and of which low-status individuals are deprived. (...) In this sense, it has resonance with the concept of social capital. The way Western societies are organized leads high status individuals to be able to reap more of the health benefits that social participation brings than are individuals lower in the hierarchy. ${ }^{90}$

The formulation of "Status Syndrome" is finally the synthesis of a long line of work carried out by American epidemiologists. It demonstrates the introduction and incorporation of the Dubos Thesis into a British public health culture still dominated by the McKeown Thesis. It introduces the prevalence of the social "role" or "capital" over absolute wealth highlighted by Cassel in his efforts to investigate the state of health of African-Americans. In line with Syme, it further expands the effect of bio-psycho-social stress to encompass the whole of the social hierarchy. In 2006, in a short paper that summarizes Status Syndrome, Marmot felt it necessary to clarify that racial inequalities in the US did not constitute an exception but, rather, reflect health disparities at "the ends of the spectrum". ${ }^{91}$ In doing so, Marmot recognises indirectly that the bio-psycho-social epidemiology he defends at the head of the WHO is originally rooted in the racial problems of the US, yet applicable to all societies.

88 Marmot/Shipley/Rose 1984.

$89 \mathrm{Marmot} / \mathrm{Smith} /$ Stansfeld/Patel/North/Head/White/Brunner/Feeney 1991, 1387.

90 Marmot 2006, 1305.

91 Marmot 2006, 1304. 
By deracializing bio-psycho-social epidemiology, Marmot did not depart, though, from the original development of the field in the civil rights movement. On the contrary, the bio-psycho-social turning point at the WHO might be seen as a strategical step aimed at using international institutions to overcome resistance from the British government. The political trajectory of the Black Report ${ }^{92}$ carried out in the UK over the course of the 1970s is representative of the political reception of bio-psycho-social epidemiology. The report was ordered by the socialist government following an open letter that Richard Wilkinson ${ }^{93}$ addressed to the Secretary of State for Social Services for the Labour Party, David Ennals, in order to make him aware of the health inequalities that persisted in spite of universal health insurance. In response, Douglas Black was asked to produce an epidemiological report on the matter that was completed in 1980. In the interim, the Thatcher government came to power and made efforts to stop the investigation that was eventually published only by a private publishing house. ${ }^{94}$ The "facts" brought to light by social epidemiologists became real political issues even up to the point where the Thatcher government tried to censor, in 1986, socio-professional categories for the ten-yearly collection of vital/health statistics, much to the indignation of the medical professionals informed by the opposition..$^{95}$ In this context, addressing social determinants of health from an international perspective, might have as appeared the only way to overcome national resistance.

\section{Conclusion}

We started this paper interrogating why several social epidemiologists employ a "rhetoric of discovery" concerning their field. The history of social epidemiology has until now been made by social epidemiologists themselves. A logic of legitimacy might have prevailed, for, by making a continuous history of their field, they inscribe it in the continuity of the celebrated historical figures (Villermé, Virchow, Chadwick) of $19^{\text {th }}$ century social medicine. But this logic of rediscovery hides crucial epistemological and transnational transformations that first started with Dubos' epistemological critiques of the scientific foundations of $19^{\text {th }}$ century social medicine. Dubos' historiographic statement had a deep impact in a US context that was both marked by a con-

92 Black 1980.

93 Wilkinson 1976.

94 Townsend/Whitehead/Davidson 1980.

95 Group 1986. 
cern for chronic disease and for racial inequalities. These transformations must be considered if we want to understand how we have come to witness a radical transformation within the WHO's strategies.

In 1978, social determinants of health were addressed in the WHO's reports as the following:

The development of strategies for health for all by the year 2000 calls for an understanding of some of the basic concepts on which resolution WHA30.43 was based. The reference in that resolution to a socially and economically productive life implies that health development both contributes to and results from social and economic development. Such development takes place in individual countries, but international action is required to support it. ${ }^{96}$

In 2008, one could read in the CSDH's report the following lines:

Just as economic growth, and its distribution, is vitally important for health, investment in health and its determinants is an important strategy for boosting economic development (CMH, 2001). Raising the health status of people lower down the social hierarchy even to the population median level of health would have a major impact on overall health and should improve a nation's productivity. ${ }^{97}$

The 1978 quote is one amongst many examples that attest to the fact that the WHO's conception of the social determinants of health was traditionally considered in terms of how economic growth is beneficial to health. The introduction of the bio-psycho-social model into the WHO's strategies announced a subtle but crucial displacement. In the second quote, the use of the words "distribution" and "social hierarchy" demonstrate that social determinants are seen from a different, and collective, perspective, i.e. the detrimental impact of unfair economy on health. This displacement presupposes that it is not material hardship, but stress associated with the role that an individual occupies in the social hierarchy, that mainly determines susceptibility to diseases. Consequently, the message that Marmot is relaying at the head of the WHO, continues, following Cassel and Syme, to promote a specific critique of the presupposition of $19^{\text {th }}$ century social medicine: the same one the Dubos Thesis promoted over McKeown's liberal thesis. It further contributes towards universalising an epistemological and finally, a political lesson learnt by addressing the persistent problem of the abnormally high mortality rate in the African-American community: if bio-psycho-social stress induced by racial and social disparities kills, then economic growth does not improve, but instead redirects health inequalities. Social justice and fair redistribution might be the only effective way of reducing the gap.

From this angle, bio-psycho-social epidemiology may indeed have been originally thought of as operating an epistemological rupture with $19^{\text {th }}$ cen-

96 WHO, Executive Board, 1978, 2.

97 CSDH 2008, 39.

Gesnerus 77 (2020) 
tury social medicine, but it remains loyal to its original political intention: As Virchow put it, politics is nothing but medicine on a grand scale.

\section{Bibliography}

Adams, James M., "Some Racial Differences in Blood Pressures and Morbidity in a Group of White and Colored Workmen", American Journal of Medical Sciences 184 (1932) 342-350

Arminjon, Mathieu, "Birth of the Allostatic Model: From Cannon's Biocracy to Critical Physiology", Journal of the History of Biology 49 (2016) 397-423

Armstrong, David, "Chronic Illness: a Revisionist Account", Sociology of Health \& Illness 36 (2014) 15-27.

Berkman, Lisa F./Ichiro Kawachi, "A Historical Framework for Social Epidemiology", in Lisa F. Berkman/I. Kawachi (eds.) Social Epidemiology (New York 2000) 3-12

Bishop, Eugene L., "Outline of Project for the Study of Negro Health in Tennessee", Public Health Reports 44 (1929) 1944-1948

Black, S. Douglas, Inequalities in Health: Inequalities in health: Report of a Research Working Group (London 1980)

Boas, Ernest, The Unseen Plague: Chronic Illness (New York 1940)

Britten, Rollo H., "Mortality Rates by Occupational Class in the United States", Public Health Reports 49 (1934) 1101-1111

Cassel, John C., "The Contribution of the Social Environment to Host Resistance", American Journal of Epidemiology 104 (1976) 107-123

Cassel, John C., "Physical Illness in Response to Stress", in: Levine Sol/Norman A. Scotch (eds), Social Stress, (New Brunswick 2013[1970]) 189-209

Chandola, Tarani/Michael C. Marmot, "Social Epidemiology", in: Wolfgang Ahrens/ Iris Pigeot (eds.), Handbook of Epidemiology (Berlin/Heidelberg 2005) 893-916

Colgrove, James, "The McKeown Thesis: A Historical Controversy and Its Enduring Influence", American Journal of Public Health 92 (2002) 725-29

Concepción, Isabelo/Emilio Bulatao, "Blood-Pressure Picture of the Filipinos", Philippine Journal of Science 11 (1916) 135-49

Condrau, Flurin/Michael Worboys, "Second Opinions: Epidemics and Infections in Nineteenth-Century Britain”, Social History of Medicine 20 (2007) 147-58

Commission on Social Determinants of Health (CSDH), Closing the Gap in a Generation: Health Equity Through Action on the Social Determinants of Health: Final Report of the Commission on Social Determinants of Health (Geneva 2008)

Curtin, Philip D., "The Slavery Hypothesis for Hypertension among African Americans: The Historical Evidence", The American Journal of Public Health 82 (1997) 1681-1686

Dubos, René, The Dreams of Reason: Science and Utopias (New York 1961)

Dubos, René, Man Adapting (New Haven/London 1965)

Dubos, René, Mirage of Health: Utopias, Progress, and Biological Change (London 1959) 
Epstein, Frederick H/ R.D. Eckoff, ““The Epidemiology of High Blood PressureGeographic Distributions and Etiological Factors.”, in: J. Stamler/R. Stamler (eds.)The Epidemiology of Hypertension (New York 1967) 155-166

Geiger, H. Jack/ Norman A.Scotch, "The Epidemiology of Essential Hypertension: A Review with Special Attention to Psychologic and Sociocultural Factors I. Biologic Mechanisms and Descriptive Epidemiology", Journal of Chronic Diseases 16 (1963) 1151-1182

Group, "Damned Lies, and Suppressed Statistics" British Medical Journal 293 (1986) 349-350.

Henry, P. James/Cassel, John C., "Psychosocial Factors in Essential Hypertension Recent Epidemiologic and Animal Experimental Evidence", American Journal of Epidemiology 90 (1969) 171-200

Irwin, Alec/ Emile Scali, "Action on the Social Determinants of Health: A Historical Perspective", Global Public Health 2 (2007) 235-256

Kardiner, Abram/Ovesey, Lionel, The Mark of Oppression: A Psychosocial Study of the American Negro (New York 1951)

Krieger, Nancy "Theories for Social Epidemiology in the 21st Century: An Ecosocial Perspective", International Journal of Epidemiology 30 (2001) 668-677

Krieger, Nancy, Epidemiology and the People's Health: Theory and Context (New York 2011)

Krieger, Nancy/Stephen Sidney, "Racial Discrimination and Blood Pressure: The CARDIA Study of Young Black and White Adults", American Journal of Public Health 86 (1996) 1370-1378

Lennard, Henry L./ Charles Y. Glock "Studies in Hypertension: VI. Differences in the Distribution of Hypertension in Negroes and Whites: An Appraisal", Journal of Chronic Diseases 5 (1957) 186-196

Levine, Sol/ Norman A.Scotch, "Introduction", in: S. Levine/N. A. Scotch, Social Stress, by (New Brunswick 2013[1970]) 1-16

Mackenbach, Johan, "The Contribution of Medical Care to Mortality Decline: McKeown Revisited", Journal of Clinical Epidemiology 49 (1996) 1207-1213

Marmot, Michael G., "Status Syndrome: A Challenge to Medicine", Journal of the Americal Medical Association 295 (2006) 1304-1307

Marmot, Michael G./George Davey Smith/Stephen Stansfeld/Chandra Patel/Fiona North/Jenny Head/Ian White/Eric Brunner/Amanda Feeney, "Health Inequalities Among British Civil Servants: The Whitehall II Study", The Lancet 8754 (1991) 1387-1393

Marmot, Michael. G./Geoffrey Rose/Martin J. Shipley/Peter G. Hamilton, "Employment Grade and Coronary Heart Disease in British Civil Servants.", Journal of Epidemiology \& Community Health 32 (1978) 244-49

Marmot, Michael G./Martin J. Shipley/ Geoffrey Rose, "Inequalities in Death - Specific Explanations of a General Pattern?", The Lancet 8384 (1984) 1003-1006

Marmot, Michael, G./Leonard S. Syme, "Acculturation and Coronary Heart Disease in Japanese-Americans", American Journal of Epidemiology 104, 3 (June 1976) $225-247$

Macintyre, Sally/Anne Ellaway, "Ecological Approaches: Rediscovering the Role of the Physical and Social Environment", In: Lisa F., Berkman/ Ichiro, Kawachi (eds), Social Epidemiology (New York 2000) 332-348 
McKeown, Thomas, The Modern Rise of Population (London 1976a)

McKeown, Thomas, The Role of Medicine. Dream, Mirage, or Nemesis (London 1976b)

McKeown, Thomas/Robert G. Brown, "Medical Evidence Related to English Population Changes in the Eighteenth Century", Population Studies 9 (1955) 119-141

McKeown, Thomas/R. Graham Record, "Reasons for the Decline of Mortality in England and Wales during the Nineteenth Century", Population Studies 16 (1962) 94-122

Meyer, B. J./W. J Pepler/A. C.Meyer/J. J. Theron, "Atherosclerosis in Europeans and Bantu”, Circulation, 29 (1964), 415-21

Moser, Marvin, "Epidemiology of Hypertension with Particular Reference to Racial Susceptibility", Annals of the New York Academy of Sciences 84 (1960), 989-999

Nathanson, Constance A., Disease Prevention as Social Change: The State, Society, and Public Health in the United States, France, Great Britain, and Canada (New York 2007)

Neser, William B./Herman A. Tyroler/John C. Cassel, "Social Disorganization and Stroke Mortality in the Black Population of the North California", American Journal of Epidemiology, 93 (1971) 166-175

Porter, Dorothy, Health Citizenship: Essays in Social Medicine and Biomedical Politics, (Berkeley 2011)

Rose, Geoffrey/P. J. S.Hamilton/Keen Harry/D. D. Reid, /Peter McCartney/R. J Jarrett, "Myocardial Ischaemia, Risk Factors and Death from Coronary Heart-Disease", The Lancet 309 (1977) 105-109

Saunders, G. Michael/Huldah Bancroft, "Blood Pressure Studies on Negro and White Men and Women Living in the Virgin Islands of the United States", American Heart Journal 23 (1942) 410-423

Scotch, Norman A., "Sociocultural Factors in the Epidemiology of Zulu Hypertension", American Journal of Public Health and the Nation's Health 53 (1963) 1205-1213

Sedgwick, Peter, "Illness: Mental and Otherwise", The Hastings Center Studies 1 (1973) 19-40

Selye, Hans, The Story of the Adaptation Syndrome (Montreal 1952)

Shaw, Bernard, The Doctor's Dilemma: With a Preface on Doctors (New York 1913)

Stone, Charles T., "The Mortality from Heart Disease: A Challenge: Chairman's Address", Journal of the American Medical Association 103 (1934) 151-54

Susser, Mervin, "Apartheid and the Causes of Death: Disentangling Ideology and Laws From Class and Race" American Journal of Public Health 73 (1983) 581-584

Susser, Mervin/Landon Myer, "Social Epidemiology”, in: Walter W Holland/Jørn Olsen /Charles du V. Florey (eds), The Development of Modern Epidemiology. Personal Reports from Those Who Were There (Oxford 2007) 207-217

Syme, S. Leonard, "Historical Perspective: The Social Determinants of Disease Some Roots of the Movement", Epidemiologic Perspectives \& Innovations 2 (2005) 1-7

Syme, S. Leonard/Lisa F. Berkman, "Social Class, Susceptibility and Sickness", American Journal of Epidemiology 104 (1976) 1-8

Syme, S. Leonard/Thomas T. Oakes/ Gary D.Friedman/ Robert Feldman/Abraham B.Siegelaub/Morris F. Collen, "Social Class and Racial Differences in Blood Pressure", American Journal of Public Health 64 (1974) 619-620 
Szreter, Simon, "Rethinking McKeown: The Relationship Between Public Health and Social Change", American Journal of Public Health 92 (2002) 722-725

Szreter, Simon, "The Importance of Social Intervention in Britain's Mortality Decline c.1850-1914: A Re-Interpretation of the Role of Public Health", Social History of Medicine 1 (1988) 1-38

Turchetti, Simone/Néstor Herran/Soraya Boudia, "Introduction: Have We Ever Been 'Transnational'"? Towards a History of Science Across and Beyond Borders, The British Journal for the History of Science 45 (2012) 319-336

Turnbull, David, "Reframing Science and Other Local Knowledge Traditions", Futures 29 (1997) 551-562

Townsend, Peter/Margaret Whitehead/Nick Davidson, Inequalities in Health: The Black Report (London 1980)

WHO, Executive Board Proposed Strategies for Attaining Health for All by the Year 2000: Report of the Programme Committee of the Executive Board 63 (Geneva 1978)

Weisz, George, Chronic Disease in the Twentieth Century. A History (Baltimore 2014)

Williams, David R., "Racial Variations in Adult Health Status: Patterns, Paradoxes and Prospects", in: N. Smelser/W. Julius Wilson/F. Mitchell (eds.) America Becoming: Racial Trends and Their Consequences (Washington, D. C. 2001) 371-410

Wilkinson, Richard, "Dear David Ennals" New Society (1976) 567-568

Wilkinson, Richard/Michael G. Marmot, Social Determinants of Health: The Solid Facts (Copenhagen 1998)

Wilkinson, Richard/Kate Pickett, The Spirit Level. Why More Equal Societies Almost Always Do Better (London 2009)

Wilson, Thomas W./Clarence E.Grim, "Biohistory of Slavery and Blood Pressure Differences in Blacks Today. A Hypothesis", Hypertension 17 (1991) I122-I128

Yankauer, Alfred, "The Relationship of Fetal and Infant Mortality to Residential Segregation: An Inquiry Into Social Epidemiology", American Sociological Review 15 (1950) 644-648 